Article

\title{
The Transformative Power of Urban Arrival Infrastructures: Berlin's Refugio and Dong Xuan Center
}

\author{
René Kreichauf ${ }^{1,2, *}$, Olivia Rosenberger ${ }^{3}$ and Paul Strobel ${ }^{4}$ \\ 1 John F. Kennedy Institute for North American Studies, FU Berlin, 14195 Berlin, Germany; \\ E-Mail: rene.kreichauf@fu-berlin.de \\ ${ }^{2}$ Cosmopolis -Centre for Urban Research, Vrije Universiteit Brussel, 1050 Brussels, Belgium; E-Mail: rene.kreichauf@vub.be \\ 3 Institute of Geography, HU Berlin, 12489 Berlin, Germany; E-Mail: rosenbma@hu-berlin.de \\ ${ }^{4}$ Institute of Architecture, TU Berlin, 10623 Berlin, Germany; E-Mail: p.strobel@campus.tu-berlin.de \\ * Corresponding author
}

Submitted: 15 February 2020 | Accepted: 11 May 2020 | Published: 28 July 2020

\begin{abstract}
Migration researchers and urban scholars are increasingly applying infrastructural approaches to analyze the production and organization of urban spaces and migration. While transformative and transforming power seem to be inherent characteristics of infrastructures, studies to date have rarely emphasized this aspect, only placing minimal focus on its importance for understanding the constitution and development of infrastructures and for examining the mobility of migrants. In the current article, we study Berlin's Refugio, an alternative form of housing for forced migrants, and the city's Dong Xuan Center (DXC), a Vietnamese hypermarket. We argue that they not only represent infrastructures in which newcomers reach a city, and navigate their trajectories, as well as the obstacles, and opportunities of urban life, but they are also 'infrastructures of conversion' that transform material space and the people inhabiting them, and their entanglement with the city. While the DXC and Refugio emerged out of necessity, addressing the lack of economic (DXC) and housing (Refugio) opportunities, they have changed into cultural and economic hubs for migrant communities and beyond. On the one hand, these changes come with multilayered negotiation processes, revealing a complex interplay of interests, actors, and internal hierarchies within the DXC and Refugio. On the other hand, their transformation illustrates the influence of local planning authorities, institutions, and the pressure to culturally and economically exploit their social, spatial, and 'ethnic' characteristics. This mesh elucidates the diffuse position of both infrastructures in the urban realm. While their existence and future development is constantly challenged, they simultaneously represent political spaces that prompt institutional logics and questions of immigrant integration.
\end{abstract}

\section{Keywords}

commodification; infrastructures of conversion; local governance; migration infrastructure; mobility; urban arrival

Issue

This article is part of the issue "Urban Arrival Spaces: Social Co-Existence in Times of Changing Mobilities and Local Diversity" edited by Yvonne Franz (University of Vienna, Austria) and Heike Hanhörster (ILS-Research Institute for Regional and Urban Development, Germany).

(C) 2020 by the authors; licensee Cogitatio (Lisbon, Portugal). This article is licensed under a Creative Commons Attribution 4.0 International License (CC BY).

\section{Introduction}

Over recent decades, scholars of migration and urban studies have increasingly paid attention to the role of infrastructural formations as "socio-technical apparatuses and material artifacts that structure, enable, and gov- ern" urban space and migration (Burchardt \& Höhne, 2015 , p. 3). As a result, various analytical concepts of infrastructure-such as 'migration infrastructure' or 'arrival infrastructure' - have emerged, aiming to study how urban life and migration is organized and to unpack the space that migration acquires (Leurs, 2019; 
Meeus, van Heur, \& Arnaut, 2019; Simone, 2014; Xiang $\&$ Lindquist, 2014). The majority of this scholarship exemplifies that infrastructures are not static, but they can expand, change, or decline, because "infrastructure is never complete" (Simone, 2014, p. 151). Meeus et al. $(2019$, p. 17) even find a "transforming nature of the infrastructures themselves." While transformation seems to be an inherent characteristic of infrastructures, particular in relation to migration, scholars to date have rarely emphasized and empirically studied this quality, only placing minimal focus on the transformative power of infrastructures and its importance for understanding their development, for the people inhabiting and using them, and for the urban realm. The purpose of the current article is thus to reveal what happens in, through, and with migration infrastructures, and to analyze what determinants, mechanisms, and practices are relevant for their transformation and for the mobility of people. We are particularly interested in the following questions: How are these infrastructures operated internally and how do they function 'inside'? To what extent do external factors such as planning regulations and institutional structures shape their development and transformation? To what degree do these infrastructures enhance or impede "people's migratory capability" in the city of arrival (Xiang \& Lindquist, 2014, p. 125)?

We examine two arrival infrastructures, which at first glance appear to be distinct: Berlin's Refugio, an alternative form of housing for forced migrants, and the Dong Xuan Center (DXC), a Vietnamese hypermarket and wholesaler. We argue that the two represent not only infrastructures where newcomers reach a city, and navigate the trajectories, obstacles, and opportunities of urban life, but they are also 'infrastructures of conversion' that include a bundle of dimensions in which their transformative and transforming powers appear and unfold. First, they quite literally 'make' places, transforming the locations and material spaces they occupy, and the functions, purposes, and meanings of these places. Second, they constantly transform the mobilities and positions of the people that inhabit and use them, producing multidirectionality of newcomers' trajectories (Meeus et al., 2019). This in turn contributes to the transformation of the material spaces of these infrastructures. Lastly, while they convert places, people, and their position, the infrastructures simultaneously convert themselves, because of their constant changes, updates, and expansions (Simone, 2014). These transformations influence local institutional approaches and perceptions, and the positionality of these infrastructures within local immigration understandings.

To understand the characteristics of conversion infrastructures, the ways in which they work, are produced, subjugate, or facilitate space and bodies, and what they transform space, bodies, and perceptions into, we study the "logics of operation" of the DXC and Refugio (Xiang \& Lindquist, 2014, p. 124) and the "infrastructuring practices" these infrastructures emerge out of and are devel- oped by (Meeus et al., 2019, p. 2). This includes, on the one hand, going backstage (Star, 1999) and studying the inner workings and rationalities of these infrastructures. Here, we particularly focus on the social and cultural networks, social practices, and negotiations that have resulted in the development of the DXC and Refugio, and that internally regulate and gradually change them, highlighting the role of "people as infrastructure" (Simone, 2004 , p. 410). On the other hand, we pay attention to the forms of urban governance and external factors in which they are embedded and are regulated by. These comprise regulatory forces (governmental institutions, policies, discourses, and non-governmental actors) as well as economic factors and logics that impact and structure the development and existence of the DXC and Refugio and the people inhabiting them. The two spheres are interlinked and overlap each other, underlining the complex and dynamic relationships of actors, interests, and practices on various scales.

The data used for the current article derives from qualitative comparative research conducted in Berlin in 2018 and 2019. The data collection prioritized actor and interest-centered analyses. We used three research methods. First, we conducted multiple site visits to the DXC and Refugio and their surrounding areas, studying the way they are used and the variety of users' practices. Second, we carried out participatory observations, examining spatial appropriations, interactions, and relationships. Third, we conducted 19 open and guidelinebased interviews (eleven at the DXC, eight at the Refugio) with (1) decision-makers and administrative bodies, such as the directors of both projects and local authorities, (2) people at both places with specific occupations, such as vendors and business owners at the DXC or social workers and employees at the Refugio), and (3) users of the spaces (residents and guests at the Refugio, and shoppers and workers at the DXC). The purpose of this approach was to gain knowledge about the living and working conditions, specific behaviors, conflicts, and relationships in the use of space, and about the development of the DXC and Refugio. Interviews were conducted in German and translated into English for this article.

In what follows, we define the mechanisms and structures that result in the transformation and diversification of these spaces and the people using them. We show that while the DXC and Refugio emerged out of necessity, addressing the lack of economic opportunities for Vietnamese Berliners in the case of the DXC and the shortage of housing for forced migrants in the case of the Refugio, they have changed into cultural and economic hubs for migrant communities and beyond. On the one hand, these changes are accompanied by with multilayered negotiation processes, which reveal a complex and adversarial interplay of interests, actors, and internal hierarchies within the DXC and Refugio. On the other hand, the transformation of the DXC and Refugio reveal the influence of local planning authorities and institutions, and the pressure to culturally and economically exploit their 
social, spatial, and 'ethnic' characteristics. This mesh finally elucidates the diffuse position of the two infrastructures in the urban realm. While their existence and future development is constantly challenged, they simultaneously represent political spaces that prompt institutional logics and questions of immigrant integration.

\section{Infrastructures and Their Transformative Power}

Infrastructure orders spaces, things, and people, and it configures and enables mobilities (Hannam, Sheller, \& Urry, 2006). While infrastructures include technological and spatial characteristics, a precise focus on infrastructures of migration exemplifies that it is not only technical or physical factors-the "immobile material worlds" (Meeus et al., 2019, p. 15)-that define infrastructures, but also "systematically interlinked technologies, institutions, and actors" (Xiang \& Lindquist, 2014, p. 122). Infrastructures are thus not simply places, institutions, sites, or artefacts, "singular, fixed or stable entities that can simply be isolated or demarcated" (Leurs, 2019, p. 92). Instead, they are "relational infrastructures" (Simone, 2014) that involve "multidirectional rationalities between different actors and entities" (Leurs, 2019, p. 94). They condition the mobility of people (as well as objects, thoughts, animals, etc.) and mediate temporary territorialization by institutions and actors whose "logics of actions collide with and contradict one another" (Xiang \& Lindquist, 2014, p. 135). This takes place in "multiple and hybrid affiliations of varying geographical reach" (Amin, 2002, as cited in Meeus et al., 2019, p. 14). Meeus et al. $(2019$, p. 1$)$ thus define infrastructures where migrants arrive, as "those parts of the urban fabric within which newcomers become entangled on arrival, and where their future local or translocal social mobilities are produced as much as negotiated." Infrastructures determine the mobility of people. Similar to a portal or to spaces of transit, people enter an infrastructure, "prepare their becoming" (Papadopoulos, Stephenson, \& Tsianos, 2008 , p. 217), and negotiate their further trajectories.

Infrastructures have different functions and purposes, depending on those who govern and use them. They include regulatory sorting or channeling functions and processes, which allow access to some and construct barriers to others (Meeus et al., 2019). Leurs (2019), for example, studies 'migration crisis infrastructures' as regulatory infrastructures that contain, control, and select people, and the unjust ways in which migration is managed. Similarly, Kreichauf (2018) defines 'forced infrastructures of arrival,' explaining cases where, by means of law, the state uses infrastructures to limit migrants' mobility and legal rights. Simone (2014), instead, focuses on the relationship of top-down and bottom-up action in constituting infrastructures. He includes the role of urban residents who put together infrastructures to produce viable forms of inhabitation from the bottom up. Xiang and Lindquist (2014) capture these various dimensions and explain five infrastructural logics of operation that constitute migration infrastructures: the social, the regulatory, the commercial, the humanitarian, and the technological. It is the "deep entanglement" of these logics and dimensions that is "key to understanding migration infrastructure" (Xiang \& Lindquist, 2014, p. 124). In this regard, Meeus et al. $(2019$, p. 2) place emphasis on "infrastructuring practices", the social practices of a range of actors and networks that establish and maintain an infrastructure. Infrastructuring practices and the logics through which an infrastructure operates reveal that infrastructures are dynamic. They need constant input, repair, updates, maintenance, and validation from a variety of involved actors to function for migratory processes (Graham \& Thrift, 2007; Leurs, 2019).

People 'go through' infrastructures, but infrastructures themselves also change because of ongoing processes of (re-)negotiation. Even though they have a particular robustness, stability, and coherence (Meeus et al., 2019), they are constantly in the making and are never complete (Simone, 2014). Infrastructuring practices (the negotiation of actors, networks, and institutions through infrastructures) result in continued restructuring and repositioning processes of the actors involved, as well as of the material spaces of infrastructures. Infrastructures can take new forms, new meanings, and a different relevance for those who use them. The logics of operation can take diversions. Xiang and Lindquist (2014), for example, determine that a social infrastructure can develop into a commercial infrastructure, which in turn can become a site of regulation. This hints at the fact that infrastructures and the people using them undergo progressions. The nature of an infrastructure is one of transformation. Infrastructures transform actors, the people using them, and their mobilities. In addition, they transform material space and the infrastructure's functions.

We believe that a more in-depth focus on these transformative powers is needed. We advocate an approach that includes this quality together with introducing the notion of 'infrastructure of conversion.' Conversion infrastructures are contested, spatially manifested, and continued negotiations and social practices of migration and mobility that result in inexorable spatial conversions and changes to these infrastructures, and to the mobilities and socioeconomic status of the people using, inhabiting, and governing them. Infrastructure of conversion does not represent a new theory or concept. Instead, it aims to, analytically and empirically, point to what is already there but has remained hidden. It pays attention to the empirical reality of migration infrastructures and illustrates that their logics of operations and infrastructuring processes are a cause of, and result in, transformations. It is through and because of these transformations, or conversions, that logics and functions, actors, negotiations, and conflicts become visible. For example, as we explain below, our cases have undergone transformations from a migrant economy and a form of housing, to cultural and economic hubs. These developments are a result of continued conversion through negotia- 
tion and infrastructuring practices that lead to certain trajectories of infrastructures and the mobilities of people. The lens of conversion allows us to see and study mediation and negotiation practices, and to reveal by whom and through what means and rationalities the development of infrastructures is determined. Putting conversion at the center of analysis, we thus gain a deeper understanding of the actual conditions and make-up of infrastructures, and of the means and practices that are relevant for their constitution and transformation. Further, we can investigate what these infrastructures are developed into, why they take a certain direction, and who and what is responsible for their trajectories. Therefore, this approach facilitates analysis of the reasons, rationales, and consequences for the development of infrastructures and migrant mobilities.

A focus on conversion processes and practices can accordingly offer clarity about the essence and functions of an infrastructure. More importantly, studying conversion from below-from the mobilities, agencies, and social relations of those who practice infrastructuring-can reveal power structures, hierarchies, interests, and territorial changes of and within infrastructures. However, this does not mean that the analysis of conversion is limited to the inner workings of infrastructures. Engaging with infrastructures through conversion can also be used as a tool to uncover the entanglement of infrastructures with (general changes in) the society and city they are embedded in, affected by, and contribute to. Through conversion, we can identify how infrastructures respond to societal organizations and trends, because conversion often takes place as a reaction and adaption to societal changes (Xiang \& Lindquist, 2014), and as we illustrate below, conversion can also be an initiator of societal change. Consequently, this approach contributes to a more diverse understanding of migration and mobility, and to current debates about the "multidirectionality of the histories and the potential futures of migrants" (Meeus et al., 2019, p. 5). It shows that infrastructures not only channel people's mobility in multiple directions, but also the future paths of infrastructures themselves.

\section{Conversion Infrastructures as Spaces of Translocality, Transformation, and Community Making}

The DXC and Refugio represent the variety of forms infrastructures can take, as well as the diversity and trajectories of newcomers arriving in cities 'through them.' In both infrastructures, migrants become entangled with the urban society; with a community where they find protection, social support, help in finding work or with a new language, and where they negotiate their future mobilities. At first glance, the two are radically different in terms of their origin and location, setup, and material appearance, as well as with regard to their meanings for different communities. Our analysis reveals, however, that they have significant similarities in the course of their developments.
The DXC is a 36-acre, covered Vietnamese hypermarket and bazar located in an industrial and commercial area in Berlin-Lichtenberg (see Figure 1). Opened in 2005 by a Vietnamese businessman who purchased the site, it has developed into "Germany's largest Vietnamese-run trade center," consisting of eight 200-meter long halls with street-like corridors flanked by mostly Vietnamese shops (Schmiz \& Kitzmann, 2017, p. 1). It has around 2,000 tenants, shop owners, and workers. The Refugio was developed by a German writer couple in 2015 as an intercultural housing project for forced migrants in cooperation with the Berlin City Mission, a welfare association involved in providing support for homeless people, and since 2015, also in the operation of refugee shelters in Berlin. It is located in a residential street in Berlin's multicultural and super-diverse district of Neukölln (see Figure 1). The five-story building houses 40 people, two thirds of whom have forced migrant backgrounds and one third of whom are native German speaking. According to a resident at the Refugio, it follows the "simple idea to not distinguish between people, but I come here and I am loved as who I am and I am appreciated for who I am." As a shared house, which aims to connect newcomers with long-established residents and to provide opportunities for their economic integration, it is frequently referred to as a pioneering project for refugees (Loos, 2017).

The emergence of the two institutions stems from people who seek, develop, and manage opportunities in precarious times (Simone, 2014). The development of the DXC is a result of the marginalized economic situation of Vietnamese Berliners because of their exclusion from Berlin's struggling labor market in the late 1990s and early 2000s, and continued discrimination; as well as the lack of Vietnamese cultural institutions in Lichtenberg, which is home to the highest number of Vietnamese Berliners (around 20,000). The Refugio was developed as a reaction to the increasing arrivals of forced migrants, providing alternative shelter for those who initially could not be accommodated by the state, particularly people from Somalia and Arab countries. The DXC is a migrantled infrastructure that emerged from the Vietnamese community's intervention, in an effort to provide labor, shopping facilities, and local amenities, predominantly serving its own community in Berlin and beyond. By contrast, the Refugio was set up by civil society and humanitarian actors serving migrants in need of accommodation, but it is also impelled by migrants who participate in the project's development. Both cases can be seen as necessities to a life in the city, as responses to and results of the lack of access to legal rights and state institutions that have failed to provide means for migrant incorporation, and as places in which people arrive and find the resources (labor, housing, and social networks) they need. For the DXC, a trader summarizes the importance of this infrastructure for newcomers:

For many Vietnamese people who do not speak the language yet and who haven't integrated themselves, 

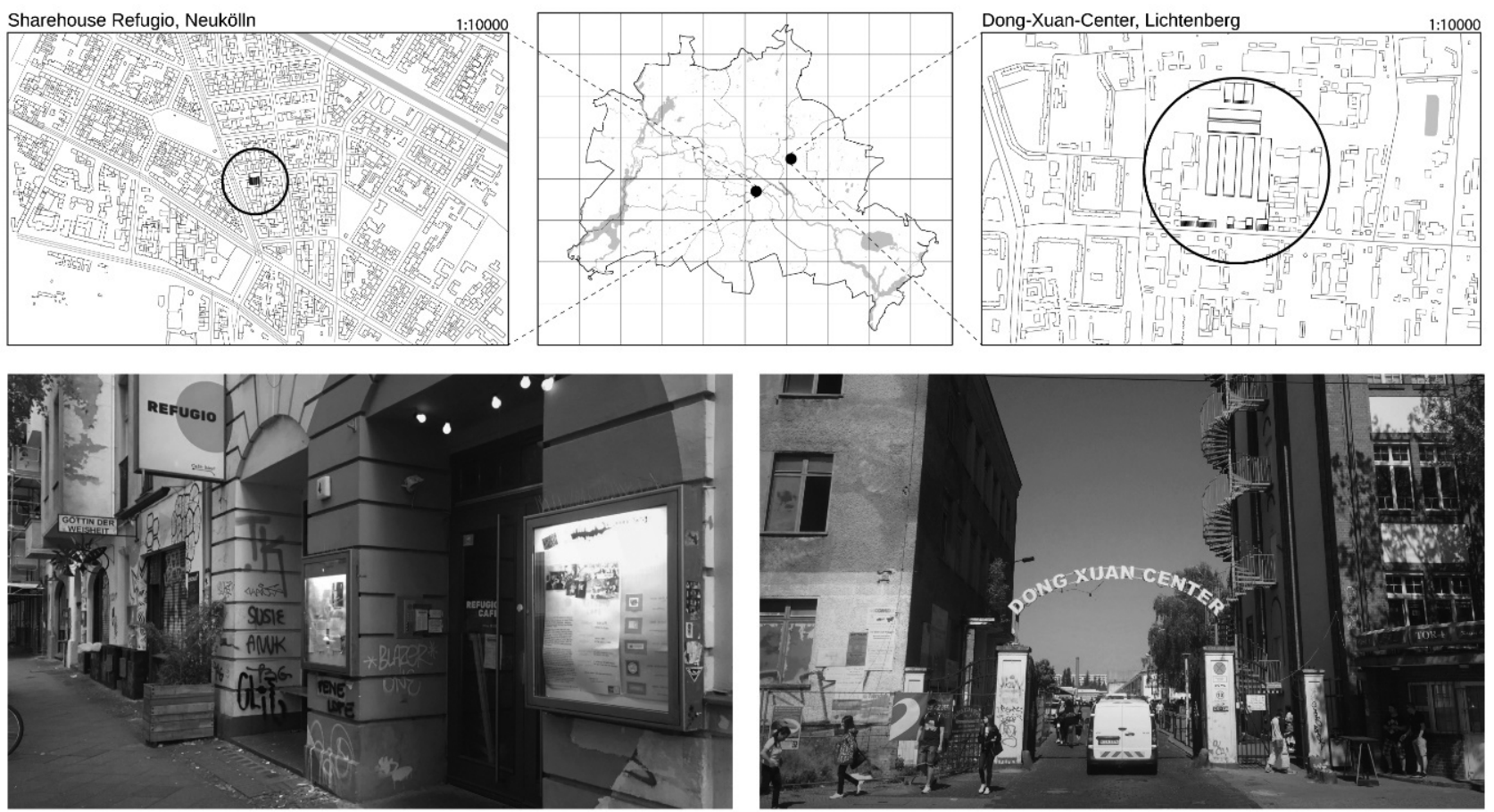

Figure 1. Location of the DXC and Refugio. Figure based on openstreetmap.org and fisbroker.

this is the central contact and starting point, because people here speak Vietnamese. There is a Vietnamese community. This is important if you have come from Vietnam, because you are directly integrated here, and you can find a job immediately. We help ourselves here and newcomers help themselves with finding jobs and making progress in their life.

As arrival infrastructures, the institutions provide services for newcomers' settling, access to information regarding employment, leisure, and education, and information on particular services for their respective communities such as language classes and places of worship. Despite their different setups and purposes, they are places in which migrants assert a collective identity, establish the validity and aspirations of a new community, and enable former and recent newcomers to feel accepted in their otherness (Pemberton \& Phillimore, 2016).

In this process, the people that inhabit and use the Refugio and DXC convert and 'make place,' both literally and figuratively. For the development of the DXC, the Vietnamese community "transformed a private, industrial, half demolished block" and heavily polluted area that once belonged a coal processing company "into a sort of public space" (Geuna \& Suraci, 2016, p. 272). With regard to the Refugio, an old retirement home was transformed into a place for multicultural community living. The ideas for the development of both cases were imported, and reflect the economic, social, and cultural structures of their origins. The founders of the Refugio developed the share house idea in South Africa and brought it to Berlin. In South Africa, they started an inter- cultural community in an old fisherman's house, serving as a place for music, art, craft work, and public events. For the DXC, the translocal functions are even more striking and architecturally evident, as the DXC is oriented toward and named after the largest covered bazar in Hanoi. The Hanoi DXC has a long-established history, reaching back to the late nineteenth century. Similar to its Berlin counterpart, it is a place for wholesale traders, shopping, and for cultural and touristic purposes. The Refugio and especially the DXC are translocal infrastructures that represent symbolic, cultural, and economic connectivity between, and embeddedness within, geographies that are specifically local, yet spatially global (Brickell \& Datta, 2011). The extent to which their translocal characteristics are visible, spatially unfold, and are practiced depends on the functions and purposes of these places. For the DXC, underlining the relation to its Vietnamese heritage through entrance signs (see Figure 1), Vietnamese lettering, and symbolism is important to make and mark it as Vietnamese place, "Berlin's little Hanoi," which aims to attract the Vietnamese community and visitors (Geuna \& Suraci, 2016, p. 271). By contrast, the Refugio is integrated into its urban surroundings, and from the outside is barely noticeable as a somewhat special place and alternative form of housing, as seen in figure 1. Spatial appropriation practices emerge inside, in the private apartments of the residents. As a refuge, a place for living, and a place of integration, the Refugio does not aim to attract spatial attention and visibility, but instead it adapts to its local setting.

Over the course of their existence, the DXC and Refugio have expanded and diversified their initial func- 
tions and purposes. The DXC has transformed from a wholesale market into a place of retail trade and for cultural, social, and leisure activities and services such as clubs, feasts, nail and hair salons, tattoo studios, bars, restaurants, Vietnamese-speaking driving schools, and supermarkets. An interviewed trader highlights the role of cultural institutions at the DXC:

We have many, many clubs. We have a women's club, we have club for businessmen, we have clubs for the respective towns and regions from Vietnam. We do a lot of community work here. We celebrate the Vietnamese New Year and have big feasts here for that. And we have a number of feasts for children. So, culturally there is something for everyone.

Because of the DXC and the concentration of Vietnamese Berliners in Lichtenberg, the district has become "the capital of Vietnamese people in Germany," as the owner of the DXC states (Nguyen Van Hien, as cited in Strauß, 2019; authors' translation). It also has changed matters of centrality, making the remote Lichtenberg neighborhood a central node for the Vietnamese community in Berlin, and internationally a place "where people know more about the DXC than they know about Berlin" (interview, Lichtenberg Councilman). As a migrant economy and "ethnic retail neighborhood," it has transformed into the economic, social, and cultural epicenter for Berlin's Vietnamese population and into a destination for tourists and Berliners, with hundreds of visitors daily (Schmiz \& Zhuang, 2016). The Refugio started as a form of transitional housing, where forced migrants were quickly (and without any bureaucracy) accommodated, and has gradually changed into a place of community and work, and a venue for public and private events and conferences. It rents out permanent office space to small companies, non-profit and migrant organizations, and has a public café.

Even though both infrastructures were developed in very different settings and with different missions, they have equally transformed into hotspots and hubs for cultural, leisure, and social activities receiving local, national, and international attention. The transformation and diversification of the Refugio and DXC beyond infrastructures that serve as arrival points for newcomers is a result of manifold conversion and negotiation practices, and the particular ambitions of the people who manage them, as well as regulatory and economic rationales. In the following, we explain the interactions of these factors and their impact on the mobility of people.

\section{The Governance of the DXC and Refugio, and the Impact on Migrant Mobilities}

The development and transformation of the DXC and Refugio highlight similar trends. They both emerged in some form of a crisis situation and out of necessity, and further expanded by establishing cultural and economic profiles and unique characteristics, filling niches and contributing to Berlin's urban fabric. This process, however, involved a transformation "into objects of intensive regulation, commodification and intervention" (Xiang \& Lindquist, 2014, p. 125). Even though both infrastructures were mostly developed from the bottom up, they are managed and organized to a large extent from the top. In this, the regulatory, socio-cultural, and economic factors at play have resulted in hierarchically organized structures within the DXC and Refugio, while externally financing structures (the Refugio), institutional regulations (the Refugio and DXC), and planning regulations (DXC) have influenced their development. The entanglement of these internal and external mechanisms is a cause of and has resulted in the conversion of these infrastructures, impacts on their further development, and transforms people's life situations and mobilities in various ways and multiple directions.

The DXC is organized by DX $\mathrm{GmbH}$, a private limited company lead by the mogul Nguyen Van Hien. DX GmbH rents out shop spaces to shop owners or tenants, providing work opportunities for predominantly Vietnamese newcomers who become employees in the shops. The hierarchy between $\mathrm{DX} \mathrm{GmbH}$, the shop owners, and the employees results in a relatively uneven distribution of social and economic capital, especially because people at $\mathrm{DX} \mathrm{GmbH}$ and shop owners are mostly members of the established Vietnamese community, while the employees are often newcomers. Informal and exploitative working conditions, including long working hours and low salaries in many cases, characterize the employment conditions. A Vietnamese graphic designer who works at the DXC explains:

A lot are illegally employed. Moonlighting. The salary is very low, between 800 and 1,000 Euro a month for at least twelve hours a day and often seven days a week. On the one hand, this is certainly exploitation. On the other hand, the Germans want to eat crispy duck for six euros.

Adding to this, a line is drawn between those who are more familiar with German bureaucracies and labor regulations, and those who are not. The inability to speak the local language and understand context-specific forms of communication make newcomers vulnerable in relation to those who have mastered these challenges. Some shop owners take advantage of the insecure and precarious situation of newcomers to ensure their businesses' economic prosperity. While employees appear to be not organized and lack a common platform to highlight their interests and problems, shop owners and tenants articulate their interests to the DXC management through business associations (Schmiz \& Kitzmann, 2017).

These hierarchical structures are nevertheless porous and allow for social mobility. Many newcomers eventually become more closely integrated in the DXC structures, often becoming tenants of shops, open- 
ing businesses at the DXC, or becoming a part of the DXC international mercantile trade, increasing their opportunities for economic advancement. Others profit from DXC's networks and relations to communities in Germany and beyond. Because of the DXC's attraction and relation to the (international) Vietnamese diaspora, it serves as a steppingstone for those whose journey and desired path lie beyond Berlin. Here, the DXC functions as a stopover and means to an end for people's further movement once an opportunity arises. Moreover, the DXC has opened up to Pakistani, Indian, Turkish, Arab, and Chinese vendors, who have started businesses at the DXC. Although the Vietnamese community still dominates the site and its cultural representation (Schmiz \& Kitzmann, 2017), there is an increasing heterogeneity of vendors, reflecting the access of the DXC to nonVietnamese (but Asian) businesses, and the multiple directions people can take.

Externally, the development of the DXC area is shaped by Berlin's and Lichtenberg's planning regulations and authorities. Lichtenberg's interference in the practices of and at the DXC was demonstrated when the aspiration to turn the center into a Chinatown-styled neighborhood by adding a cultural center, social facilities, and housing units was intervened in by the district. Lichtenberg authorities rejected the DXC's requests to change the official land use from industrial to mixed-use, impeding Van Hien's desire to transform the DXC into a Vietnamese neighborhood; an 'Asia town' functioning as a place for social life, trade, culture, and tourism. The district did so, because it has officially stated that the DXC plans would increase rents and housing prices, because it wants to preserve the area for production firms, and because it wants to protect existing retail traders in the district. However, in an interview, a Lichtenberg's city council member revealed that another reason is the fear of migrant concentrations and the development of 'parallel societies' in line with an assimilatory integration paradigm:

The DXC developers have a lot of ideas and want to develop a Chinatown-style neighborhood with housing, business areas, kindergartens, and everything a neighborhood needs. But I don't want this kind of seclusion. We from the district don't think that such an enclosed society would be beneficial but would only result in a parallel society.

The district's reservations limit the further agglomeration of the DXC and the legalization of already existing but unauthorized uses, such as gastronomy and retail. However, the DXC has formed alliances with neighboring companies that have resulted in the setting up of new channels of political communication. The importance of the market, which has become one of the major taxpayers in Lichtenberg, and its rising popularity as a tourist attraction have added to the reshuffling of power relations between the DXC and local authorities. The DXC's power in negotiating its interests resulted in the opening of a hotel in 2017, as well as building permission for the Dong Xuan House, planned to host events and provide guest rooms. Nevertheless, Lichtenberg still limits DXC's hope to develop housing and more cultural institutions on its land.

The development of the Refugio has similarly been affected by internal hierarchies and external institutional structures. Since 2017, the Berlin City Mission has exclusively operated the Refugio through a house management operation comprising City Mission employees. As the owner of the building, it sets the terms for the Refugio's spatial usage and community living. The management finalizes the rental contracts with the residents, including obligations to contribute to the organization of the house. Residents are encouraged to participate in house and floor council meetings, in which decisions are made about the house order, cleanliness, and the usage of space. Contractually, residents also have to undertake volunteer work for four hours a week, for example in the café, the maintenance of the house, or in support of other residents. The house management can dismiss residents who do not meet their obligations. It also decides on the resident structure of the house and who fits best into the community, specifying the ratio of one third native German speakers and two thirds people with forced migrant backgrounds, in an aim to regulate the 'social mixing' of residents. Social mixing is also promoted in the distribution of apartments in the Refugio, where the City Mission prohibits migrant concentrations on each of the floors. The strict regimen of rules demands a strong commitment from the residents, as a former resident explains in an interview: "You are welcome when you believe in these rules. If you don't believe in these rules, this is not the place for you."

While the Refugio describes itself as a participatory and community-oriented project, participation is implemented and organized from the top-down and a number of decisions are not made in participatory processes, but over the heads of the residents. One resident explains:

There was a problem with the design of the floor for the roof terrace. There were many ideas, but the City Mission wanted to install concrete slabs. We were all against it, but they did it anyway.... What about participatory democracy? But I understand they wanted to make it as cheap as possible.

Hierarchical power structures and decision-making processes often result in frustration and questioning the participatory organization. In addition, there are unequal power balances among the residents, because of different language capabilities, identifications with participatory structures, and motivations for living at the Refugio. German residents are more involved in contributing at decision-making platforms and in the organization of the house, resulting in a situation where the interests of forced migrants are underrepresented. For German res- 
idents (mostly students and young professionals), living in the Refugio and participating in its community structures is often a conscious lifestyle decision. By contrast, for many migrant residents it only serves as a means for housing, due to the lack of alternatives. The regulations of the house, together with the strict resident ratio, are problematic, as they make apparent the dichotomy between 'Germans' and 'migrants,' and the perceptions of who a native German speaker or a forced migrant is. The regime of community and participation also neglects the real needs and hardships for migrant residents, who often do not have the time, resources, or emotional capacities to adapt to the Refugio's intense community structures. Many migrant residents are also in asylum proceedings or have uncertain residence status, and thus few of the same rights and choices. The management and residents address this situation. Some migrant residents who do not identify with the participatory structures find other means to communicate their concerns and needs. As one interview partner states: "Our bosses, well, I talk with them and propose my ideas and concerns, sometimes daily. And they usually take it seriously." Some bypass participatory floor and house meetings and directly approach the house management team; a practice tolerated by the management. Even though the management and residents are aware of these imbalances, they have not yet found an adequate strategy, and focus more on trying to give migrant residents an understanding of the implemented structures (often obligatory) rather than adapting to their needs and situation. This is also because the Refugio is embedded in institutional and social structures, "where social and political rights depend on one's citizenship status" and where residents with German citizenship and forced migrants "cannot function as co-equals" (Mayer, in press).

The ambiguous ways in which the access to-and housing in -the Refugio are organized, foster the mobilities and trajectories of migrant residents. The majority of those who initially arrived have become permanent residents, having lived at the Refugio for a couple of years now. This development contradicts the institution's initial purpose to be a place of transition. On the one hand, this has resulted in a certain 'upgrade' and social mobility in Refugio for many migrant residents, in which they become more closely entangled in the place's structures, for example as employees in the café. Some of them stay at the Refugio for lifestyle reasons and community seeking, despite having other housing options. On the other hand, there are also permanent residents who do not actively participate in its structures and do not equally change their position within the Refugio as others do. This is often because their interest in living at the Refugio results from barriers to moving out. A smaller number of (former) residents, temporary stayed at the Refugio, and profited from its networks, interpersonal relationships, and access to information relevant for them to move. The case of the former residents Samer and his wife illustrates this process exemplarily. They arrived in
Berlin in 2015, and while living at the Refugio, started a catering service for events being held at the house. Learning about the German requirements to become self-employed entrepreneurs, Samer and his wife finally opened a Syrian restaurant in Berlin-Schöneberg in 2019. Here, the Refugio represents a place of transition, in which Samer and his wife 'transformed' from mere residents in need of shelter on arrival, to economic subjects and entrepreneurs.

In all the cases, we see the regulatory and social forces of these conversion infrastructures. The way in which they shape people's mobility and 'convert' their trajectories is rarely linear, but strongly depends on the individuals' situations, experiences, and desires to navigate their trajectories, as well as the internal and external structures of the places. The DXC and Refugio are infrastructures that channel people and their mobilities, privileging and enhancing access to various paths and opportunities for some as well as impeding migratory mobility and constructing barriers to others (van Heur, 2017). The channeling functions of the DXC and Refugio work differently. The Refugio regulates mobility through participatory social and institutional-but top-downstructures, which may result in the migrants' inclusion in these structures or the retreat from them, or may enable them to move on while maintaining continued relations to the Refugio. In the case of the DXC, we only focus on those who have a specific occupation at the market (shop owners and tenants), and find that employment conditions and economic positions hierarchically regulate mobility, while having the potential to allow for multiple directions within and beyond the DXC.

\section{Conversion Infrastructures as Places of Commercialization}

The regulatory governance of the DXC and Refugio follow economic logics and increasingly financial motives. With regard to the DXC, assistance in the process of arrival is not offered due to universal solidarity within the community, but is in fact based on the mutual fulfilment of each other's needs. An interviewed DXC trader underlines this observation: "If you come from Vietnam, you find a community here that helps you.....And for us traders, this means we have more opportunities to employ workers." While newcomers are looking for quick opportunities for employment, shop owners are in search of cheap and flexible labor. The DXC functions as a cultural hub, but has attracted (supra-)regional attention for being unique and culturally valuable for Vietnamese and other people, which in turn has made it an 'insider tip' for many Berlin tourists. This popularity is also a result of and partly grounded in the motivation of Vietnamese entrepreneurs to capitalize on the DXC's cultural features, providing visitors with authentic 'Vietnam experiences.' The financial and economic rationales are also reflected in the transformation of the market itself. The diversification of the wholesale center into a multipurpose bazar 
attracting a broad variety of visitors can be read as a component of the owner's expansion strategy. The promotion of the center as a cultural hub is therefore also utilized as a measure to increase the numbers of visitors, thereby ensuring the prosperity of the wholesale and retail operations.

Similar to the DXC but on a smaller scale, there has been a commercialization of the Refugio's cultural and social characteristics. The opening up of the Refugio by providing Berlin's migrant communities with open language cafés, counseling meetings, and by renting out space to small companies, organizations, and for external events have resulted in the Refugio becoming a social and cultural hub. However, this strategy is linked to economic rationales. The City Mission rents the space to the Refugio. In turn, the Refugio pays for this through the rent from residents and small businesses, and from events. In the past, the Refugio often struggled to cover its expenses and to pay its rent to the City Mission. As a result, the City Mission has pushed the Refugio management and residents to generate greater revenue, by renting out more space for business and events. This strategy will ultimately ensure the financial existence of the project, but it contradicts and endangers its initial ambition of being a multicultural, participatory communal housing project that creates solidarity (Baban \& Rygiel, 2017). Consequently, the German couple who founded and managed the Refugio until 2017 were replaced, and the community work- which up to then had occupied a large proportion of the City Mission's employees in the Refugio-changed into administering events and rentals. A social worker who has been working at Refugio for the past few years criticized this development:

The soul of this project has changed....And I believe if the management is more concerned with the profitability than it is with the community, it is not really conducive for a project like this....And it is also difficult for residents when the management only embodies administration, rental contracts, and all these aspects, where some residents may not even dare to approach them.

For both institutions, the increasing pressure to establish themselves as attractions and to become and remain viable has characterized their conversion (Cave, Ryan, \& Panakera, 2003). The commodification of culture and of the particular characteristics of the DXC and Refugio, as well as the reproduction of ethnicity, is important for their survival and advancement (Lee, 1992). The Refugio has to monetize its community and cultural character in order to maintain its participatory and communityoriented characteristics. It has to open the house up for external uses and provide services to refinance the project and make it profitable for the City Mission. The DXC applies and emphasizes particular cultural and ethnic characteristics (Asia Town, Little Hanoi, etc.) to further expand, increase acceptance, and attract the non-
Vietnamese visitors necessary for its further development. The Refugio's development from a socio-cultural infrastructure into a commercial one and DXC's diversification from a mere economic to a multipurpose urban space-encompassing economic as well as cultural functions-have resulted in the growing importance of these infrastructures. However, this transformation also exposes them more to regulatory institutions and financial, bureaucratic, and legal pressures, which put their existence and further development on shaky ground: The contract between the Refugio and the City Mission is annually negotiated and can potentially be terminated at short notice and the DXC continues to develop social and cultural usage on its land without legal permission. So far, authorities have turned a blind eye to these developments, probably because they see the advantages of the DXC for Lichtenberg. However, they could restrict them altogether. The two institutions depend on the courtesy and willingness of the local authorities and the City Mission, which may change with different political will and actors.

\section{The Potential of Conversion Infrastructures}

In this article, we contribute to current migration and urban studies debates on infrastructures by particularly focusing on their transformative power and their workings as infrastructures of conversion. We believe that this approach allows for a more comprehensive and deeper understanding of the constitution and operation of infrastructures and their functions. This angle enables us to unravel the rationalities and consequences of the emergence and development of infrastructures, in which we give evidence that they produce and are produced by continued conversion practices that impact on their material space, their meanings and missions, and the people inhabiting them. With regard to our cases, these illustrate that conversion infrastructures can take very different shapes and functions. The DXC and Refugio emerged from profoundly distinct circumstances and origins, and with diverse missions, yet their transformations illustrate significant similarities. While they initially started as a social infrastructure (the Refugio) and migrant economy (the DXC) aiming to serve 'their own' communities, they have transformed into cultural and commercial infrastructures that attract a broader audience. They have simultaneously become sites of intense regulation that results from the entanglement of internal structures and hierarchies, as well as from external factors such as local authorities and institutions. Of course, this development raises the question of the extent to which migrant-produced or migrant-impelled conversion infrastructures generally face commercialization along their transformation, and how much these processes precisely shape migrant mobilities. While in this article we are only able to provide a limited view on the trajectories and directions of migrants inhabiting and using the DXC and Refugio, we do provide some evidence that the way in 
which conversion infrastructures transform changes the positions and paths of migrants.

The evolution of the DXC and Refugio confirms the importance for scholars to analyze the transformative characteristics of infrastructures, and the determinants and mechanisms relevant to their transformation. As infrastructural approaches become more relevant in studying the organization of urban life and migration, a focus on conversion also helps us to understand and explain the general negotiation of social, cultural, and economic questions (Schnitzler, 2016). Conversion infrastructures exemplify exercises of power that not only constitute infrastructures, but that are also a response to developments in society. They illustrate attempts at place making and claims to the city, because in our examples, they emerged as a reaction to the lack of economic and cultural opportunities for Vietnamese Berliners and the absence of valuable forms of housing for forced migrants. Their conversion reveals the infrastructures' attempts to maintain and expand their positions in the urban realm, but also shows the pressures and rationalities they are confronted with to do so. The practice of conversion exemplifies the negotiations about the sovereignty of the two infrastructures and the constant struggle about who and what decides their functions and future directions. Their conversion has resulted in both infrastructures becoming central players in the representation of migrant communities and cultures in Berlin. This position is a result of-and comes with-regulatory and economic forces and structures, but also with power.

The DXC and Refugio have become political terrains that defy normative social rules, governmental structures, and assimilatory understandings of migrant integration. Examples of this include the debate on social mixing and the problematization of the voluntary concentration of immigrants (the Refugio), and the fear of ethnic closures and closed parallel societies (the DXC). In both cases, people contest these regimes and question their purposes. Despite Lichtenberg's resistance, the DXC has begun the development of more cultural facilities. A new market hall was opened in 2018, but contrary to the requirements of the district's building regulations, it is used for cultural events. If controlled by authorities, the DXC pays the penalty charge and "continues the party" (Lichtenberg Councilwomen Birgit Monteiro, as cited in Koch-Klaucke, 2019; authors' translation). In the Refugio, we observed many concentration tendencies despite the official house rules, and some migrant residents have found ways to circumvent the top-down implemented and strict structures of participation and decision-making processes to negotiate their interests. The Refugio has also developed into a place of urban protest against racism, the restrictions of asylum laws, and the treatment of forced migrants. In both cases, people develop agency, question conditions and societal rules, and appear as political subjects. Conversion infrastructures are created through social relations and practices that have been developed in and as a result of move- ment. Because of their transformative power, they have the opportunity not only to quickly adapt to changing circumstances, but to also become political arenas for city making.

\section{Acknowledgments}

We would like to thank Prof. Bas van Heur for scientific guidance and helpful comments in preparing this manuscript. We also wish to thank the three anonymous reviewers from Urban Planning for their critical engagement with and helpful comments about our article. We are extremely grateful to all the interview partners for their relevant insights and for participating in our research.

\section{Conflict of Interests}

The authors declare no conflict of interests.

\section{References}

Baban, F., \& Rygiel, K. (2017). Living with others: Fostering radical cosmopolitanism through citizenship politics in Berlin. Ethics \& Global Politics, 10(1), 98-116.

Brickell, K., \& Datta, A. (2011). Translocal geographies. Spaces, places, connections. London and New York, NY: Routledge.

Burchardt, M., \& Höhne, S. (2015). The infrastructures of diversity: Materiality and culture in urban space. An introduction. New Diversities, 17(2), 1-13.

Cave, J., Ryan, C., \& Panakera, C. (2003). Residents' perceptions, migrant groups and culture as an attraction: The case of a proposed Pacific Island cultural centre in New Zealand. Tourism Management, 24(4), 371-385.

Geuna, A., \& Suraci, N. (2016). Inside Dong Xuan Center: Vietnamese quasi-street in Berlin. In Street forming/re-forming. Transforming the 21st century city streets conference report (pp. 271-280). Zouk Mosbeh: Notre Dame University Louaize.

Graham, S., \& Thrift, N. (2007). Out of order: Understanding repair and maintenance. Theory, Culture, Society, 24(1), 1-25.

Hannam, K., Sheller, M., \& Urry, J. (2006). Editorial: Mobilities, immobilities and moorings. Mobilities, 1(1), 1-22.

Koch-Klaucke, N. (2019, January 22). Asia-Center Lichtenberg Das neue Reich des Herrn Hien [Asia Center in Lichtenberg. The new empire of Mister Hien]. Focus Online. Retrieved from https://www.focus.de/ regional/berlin/berlin-asia-center-lichtenberg-dasneue-reich-des-herrn-hien_id_10216933.html

Kreichauf, R. (2018). From forced migration to forced arrival: The campization of refugee accommodation in European cities. Comparative Migration Studies, 6(7), $1-22$.

Lee, D. O. (1992). Commodification of ethnicity: The so- 
ciospatial reproduction of immigrant entrepreneurs. Urban Affairs Quarterly, 28(2), 258-275.

Leurs, K. (2019). Migration infrastructures. In K. Smets, K. Leurs, M. Georgiou, S. Witteborn, \& R. Gajjala (Eds.), The Sage handbook of media and migration (pp. 91-102). London: Sage.

Loos, K. (2017). Refugio Berlin. In W. Schiffauer, A. Eilert, \& M. Rudloff (Eds.), So schaffen wir das-Eine Zivilgesellschaft im Aufbruch. 90 wegweisende Projekte mit Geflüchteten [This is how we can do it-A civil society on the move. 90 pioneering projects with refugees] (pp. 41-43). Bielefeld: transcript Verlag.

Mayer, M. (in press). The rise of the "solidarity city." Multiple agencies and contested meanings. In R. Kreichauf \& B. Glorius (Eds.), The city and asylum: Theoretical approaches and empirical findings, urban geography. Abingdon-on-Thames: Taylor \& Francis.

Meeus, B., van Heur, B., \& Arnaut, K. (2019). Migration and the infrastructural politics of urban arrival. In B. Meeus, B. van Heur, \& K. Arnaut (Eds.), Arrival infrastructures. Migration and urban social mobilities (pp. 1-32). Basingstoke: Palgrave Macmillan.

Papadopoulos, D., Stephenson, N., \& Tsianos, V. (2008). Escape routes. Control and subversion in the twentyfirst century. London: Pluto Press.

Pemberton, S., \& Phillimore, J. (2016). Migrant placemaking in super-diverse neighbourhoods: Moving beyond ethno-national approaches. Urban Studies, 55(4), 733-750.

Schmiz, A., \& Kitzmann, R. (2017). Negotiating an Asiatown in Berlin: Ethnic diversity in urban planning. Cities, 70, 1-10.
Schmiz, A., \& Zhuang, Z. C. (2016). Ethnic retail neighbourhoods: Place making and branding (RCIS Research Brief No. 2016/1). Toronto: Ryerson Centre for Immigration \& Settlement.

Schnitzler, A. v. (2016). Democracy's infrastructure: Techno-politics and protest after apartheid. Princeton, NJ: Princeton University Press.

Simone, A. (2004). People as infrastructure: Intersecting fragments in Johannesburg. Public Culture, 16(3), 407-429.

Simone, A. (2014). Relational infrastructures in postcolonial urban worlds. In S. Graham \& C. McFarlane (Eds.), Infrastructural lives: Urban infrastructure in context (pp. 17-38). London: Routledge.

Star, S. L. (1999). The ethnography of infrastructure. The American behavioral scientist, 43(3), 377-391.

Strauß, S. (2019, January 18). Dong Xuan Center in Lichtenberg. Nach Vietnam mit der Tram [Dong Xuan Center in Lichtenberg. With the Tram to Vietnam]. Focus Online. Retrieved from https://www. focus.de/regional/berlin/berlin-dong-xuan-centerin-lichtenberg-nach-vietnam-mit-der-tram_id_ 10205043.html

van Heur, B. (2017). Creative cities and the infrastructural fragmentation of socioeconomic space. In I. van Damme, B. de Munck, \& A. Miles (Eds.), Unlocking the creative city: Re-assembling why cities are agents of change and innovation (pp. 261-270). London and New York, NY: Routledge.

Xiang, B., \& Lindquist, J. J. (2014). Migration infrastructure. International Migration Review, 48(1), 122-148.

\section{About the Authors}

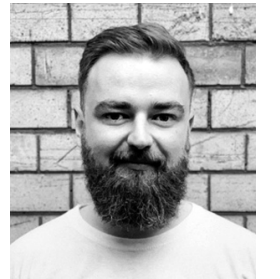

René Kreichauf is an Urban Sociologist with research and publication experiences in the fields of urban studies and migration research. He is a PhD candidate at Cosmopolis-Centre for Urban Research (Vrije Universiteit Brussel) and at the Graduate School of North American Studies (FU Berlin) including visiting researcher positions at the Global Urban Studies Program (Rutgers University-Newark) and Baruch College (The City University of New York). In his current project, he studies the development of local policies in response to the increased arrival of forced migrants in European and U.S. cities.

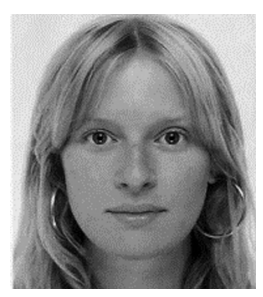

Olivia Rosenberger has a bachelor's degree in Urban and Regional Planning and is currently studying Urban Geography for her master's degree at HU Berlin. In her studies, she has developed a special interest in state and non-governmental spaces for housing refugees. In her BA thesis she investigated the potentials and limitations of inclusive housing projects for refugees.

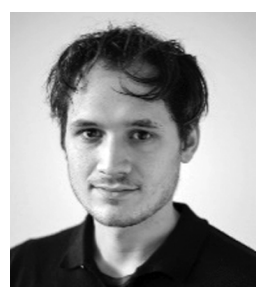

Paul Strobel holds a BA in Urban and Regional Planning and is currently completing a master's degree in Urban Design at the Department of Architecture, TU Berlin. His focus rests on present and future transformations of (ex-)urban areas with special regard to the role various infrastructures take in associated processes of adaption and conversion. 